STUDI

FRANCESI

\section{Studi Francesi}

Rivista quadrimestrale fondata da Franco Simone

185 (LXII | II) | 2018

OCTAVE MIRBEAU: UNE CONSCIENCE AU TOURNANT

DU SIEECLE - sous la direction de Ida Merello

\title{
MARIA BENEDETTA COLLINI, éclats de mythes dans la poésie symboliste
}

Marie Gaboriaud

\section{(2) OpenEdition}

Journals

Édition électronique

URL : https://journals.openedition.org/studifrancesi/13929

DOI : 10.4000/studifrancesi.13929

ISSN : 2421-5856

Éditeur

Rosenberg \& Sellier

Édition imprimée

Date de publication : 1 août 2018

Pagination : 351

ISSN : 0039-2944

\section{Référence électronique}

Marie Gaboriaud, "MARIA BeNEDETTA ColuIn, éclats de mythes dans la poésie symboliste », Studi Francesi [En ligne], 185 (LXII | II) | 2018, mis en ligne le 01 août 2018, consulté le 15 novembre 2021. URL : http:// journals.openedition.org/studifrancesi/13929; DOI : https://doi.org/10.4000/studifrancesi.13929

Ce document a été généré automatiquement le 15 novembre 2021.

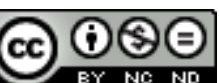

Studi Francesi è distribuita con Licenza Creative Commons Attribuzione - Non commerciale - Non opere derivate 4.0 Internazionale. 


\title{
MARIA BENEDETTA COLLINI, éclats de mythes dans la poésie symboliste
}

\author{
Marie Gaboriaud
}

\section{RÉFÉRENCE}

MARIA BENEDETTA COLLINI, éclats de mythes dans la poésie symboliste, Milano, Mimesis

Edizioni, 2016, «Multiples», 256 pp.

1 La présente étude suit le mythe à travers ses manifestations complexes et fructueuses dans la poésie symboliste. Maria Benedetta Collini choisit comme critère déterminant de son étude la définition saussurienne du mythe comme nominatio: seules les œuvres dans lesquelles les mythes sont explicitement nommés y seront pris en compte. Le corpus retenu se compose, en outre, uniquement de «poésie pure», les textes «de genre ambigu» étant laissés de coté, corpus au sein duquel l'auteure entend mener «une analyse des modalités expressives et thématiques» (p. 21) et du «jeu combinatoire» des différents «accessoires» mythiques (p.18). Retraçant également l'usage du mythe en littérature, elle rappelle entre autres la triple dimension que celui-ci revêt chez les Romantiques, à la fois comme thème, comme élément métaphysique et comme élément linguistique, ainsi que l'usage novateur qu'en fait Baudelaire, qui l'inscrit dans sa poétique des correspondances, et l'exalte comme valeur de l'artificiel et de l'imagination, arme contre le naturel et la contingence. La poésie symboliste permettrait, à son tour, de reconfigurer l'opposition chère au XVIII ${ }^{\mathrm{e}}$ siècle entre mythos et logos, qui plaçait le mythe du côté de l'erreur et de la fiction, dans une dialectique l'opposant à la raison. L'ouvrage s'organise ainsi selon trois aspects innovants dans l'emploi du mythe dans la poésie symboliste: enchevêtrement avec l'art, logique combinatoire et dimension linguistique.

2 La première partie de l'essai s'intéresse à la «double fonction du mythe, autoréférentielle et métaphysique» (p.42), en tant qu'il est utilisé, par les Symbolistes, comme comparant pour la poésie, pour la réalité contemporaine, et pour l'âme 
humaine. La première fonction du mythe serait en effet autoréférentielle, qu'il soit utilisé comme projection de l'art poétique - poésie et mythe "partage[a]nt les mêmes finalités métaphysiques» (p.59) - ou d'autres formes d'art. M.B. Collini souligne en effet l'«importance de la dimension ekphrastique pour la poésie décadente» (p. 60). En ce qui concerne les éléments de la réalité contemporaine, même si certaines figures, comme Sarah Bernhardt, sont évoquées à travers le matériel thématique du mythe, ce dernier peut aussi «se gâcher et perdre sa splendeur idéale s'il est rapproché à la contingence» ou mis en contact «avec la réalité spleenétique» (p. 65) chez Baudelaire.

La deuxième partie est consacrée à toutes les formes d'hybridation liées à l'utilisation du mythe. Rappelant que l'écriture symboliste, à la suite de Baudelaire, est fondée sur le «rapprochement entre des éléments apparemment disparates» (p. 109), l'auteure trace d'abord la présence des monstres et créatures hybrides, qui prennent souvent une forme féminine: chimère, sirène, sphinx, et autres Mélusine. Elle soulève ensuite la question de l'hybridation des mythes eux-mêmes, les textes faisant appel à des «créatures appartenant à des univers [...] disparates» qui sont «fusionnés pour des finalités esthétiques» (p. 124). Enfin, ce sont les mécanismes d'emprunt, de reprises ou d'ironie par rapport aux récits mythiques initiaux qui sont interrogés; de fait, les poètes symbolistes «plient» les données des mythes «à leurs nécessités», et «s'amusent à les déformer, à les renverser, à leur inventer une conclusion différente» (p. 144). À ce titre, M.B. Collini remarque que, d'une part, les changements effectués sont toujours assez minimes (p. 145), contrastant avec la volonté affichée des auteurs de choquer, et que, d'autre part, ces transformations sont le plus souvent des noircissements, des désacralisations.

4 Enfin, l'auteure envisage une autre composante: le lecteur, entité avec laquelle le poète symboliste a un rapport complexe. Rappelant que le mythe s'inscrit, dans sa forme initiale, dans un contexte d'énonciation différent de celui de la publication des poèmes symbolistes, elle affirme que le lectorat de ces derniers a généralement une bonne connaissance des mythes antiques et bibliques, ce qui pousse les poètes à chercher des personnages mineurs, des mythes insolites, des variantes peu connues des mythes, «autant pour faire étalage de leur érudition que pour défier le lecteur» (p. 165). Le mythe est enfin étudié comme emblème et ornement du texte, et comme nomination, à travers son pouvoir suggestif et les jeux contrastifs qu'il permet. In fine, les deux fils rouges qui sous-tendent ce voyage à travers les mythes du Symbolisme sont, d'une part, la «logique combinatoire», et de l'autre la «dimension langagière» (p.221) qui les travaillent. En tant qu'il utilise le mythe comme instrument linguistique dans sa quête métaphysique de l'absolu, le moment symboliste constituerait ainsi un jalon important dans l'histoire du mythe dans la littérature, puisqu'il permet de réconcilier logos et mythos. 